complete register to be made of the foods consumed by various birds and their consequent effect on crops, gave an example of how children can oontribute to scientific knowledge. A film illustrating the effect of energy expenditure on blood circulation and showing the function of the spleen, and a clear exposition of Lena Stern's method of treating shock extended the programme to the field of medicine.

The final film, "Experiments on the Revival of Organisms", was undoubtedly the most impressive. After a brief and exceptionally clear pictorial explana. tion of the function of the heart and lungs, the film leads up from the artificial setting in motion of an individual organ, the heart, to the revival of a dog's severed head and finally to the revival of the animal itself, from which the blood has been completely drained off and the heart-beats and respiration of which had ceased for ten minutes. The blood is re-circulated by means of an artificial circulatory system, the 'autojector', the deceased animal heaves its first sigh, heart-beats and respiration begin to register, and, after a short time, the autojector is disconnected and life proceeds. Within a few days the dog is its normal self again and, as the film shows, "lives happily ever after". The producers are to be congratulated on the skill and beauty of this film, which, while maintaining full scientific clarity throughout, nowhere offends the resthetic senses, opens up an unlimited perspective of scientific advance and cannot fail to instil into the most unimaginative minds a profound respect for scientific effort and achievement. The commentary to the films was prepared by Prof. J. B. S. Haldane.

Mr. Arthur Elton, in his opening remarks, dwelt on the systematic way in which the popularization of science is treated in the U.S.S.R. and stressed the necessity of a scientific approach on the part of the whole population in the interests of the maximum war effort. This view was expanded in an introduetory lecture by Dr. M. Ruhemann, who pointed out that, in the U.S.S.R., the diffusion of scientific knowledge and a scientific approach to life has always been considered a matter of urgent necessity, whereas we have tended rather to regard it as a luxury. Reviewing Soviet methods of popularizing science, in books, newspapers, in children's clubs and on the collective farms, he directed attention to the lack of scientific and technical knowledge among young people in Great Britain, due to a large extent to an antiquated school currieulum, and to the tragic consequences which this is bound to have on the efficiency of our Forces in a highly mechanized war. Mr. D. N. Pritt moved a vote of thanks to the speakers and the promoters of the meeting, which was so well supported that large numbers had to be turned away. A repetition of the exhibition is being considered.

\section{Imperial Institute}

The extensive facilities available at the Imperial Institute, London, S.W.7, for the rapid supply of technical information relating to the trade, occurrence and utilization throughout the world of all kinds of raw materials, and the scope of the intelligence service are not so well known as they should be. The Institute's staff includes tropical agriculturists, chemists, chemical technologists, economic botanists, economic geologists, mining engineers, mineralogists and statisticians, and, when desirable, the Institute seeks the advice of members of its fifteen consultative committees. Further help is also afforded by numer- ous irade eontacts. The Institute also has an extensive reference library and a technical index covering most of the relevant trade and scientific publica. tions issued during the past thirty years. The Institute can deal with inquiries relating to sources of supply of, and other information relating to, raw materials and semi-manufactured products whether of animal, plant or mineral origin in all countries, cultivation of crops and the soil and conditions under which they have to be grown, methods employed in mining, smelting and dressing minerals for the market, and so on. Analysis and testing of samples of raw materials is undertaken in the laboratories of the Institute. Inquiries should be made in the first instance to the Intelligence Section of the Plant and Animal Products Department or of the Mineral Resources Department, according to the nature of the subject concerned. No charge will be made for services to Departments of the United Kingdom Government or other Governments of the Empire contributing to the general funds of the Institute unless a particular inquiry involves a volume of work so great that it cannot be undertaken by the existing staff.

\section{The Rockefeller Foundation}

DURING 1941 the Rockefeller Foundation appropriated more than nine million dollars for public health, medical sciences, natural sciences, social sciences, humanities and a programme in China. The work in public health received the largest appropriation-2,450,000 dollars. Medical sciences came next with 2,120,000 dollars. The Foundation distributed $1,938,300$ doses of yellow fever vaccine to the United States Government and 1,972,386 doses to Africa. Including the total sent to India, Brazil and Singapore, the Foundation gave a grand total of 4,260,680 doses of its own manufactured yellow fever vaceine. The Paris office of the Foundation closed in July I941, and there are now no Foundation representatives on the Continent of Europe, though an office is being maintained in London. The Far Eastern office was removed from Shanghai to Manila late in 1940. Important studies are being carried out in Malta, in Trinidad and on the Burma Road.

\section{Detection of Cracks in Engineering Materials}

A VALUABLE development in the use of fluorescent light is its application to the detection of flaws or cracks in engineering materials, and a demonstration showing its effectiveness was recently given by Colloidal Research Laboratories, 66-70 Petty France, London, S.W.1. 'Their 'Glo-Crack' system, as it is named, marks a great advance on existing methods and makes the detection of the least visible form of crack as nearly as possible a certainty. The articles to be examined are first immersed for a short period in a hot bath of fluorescent material. They are then transferred to a second bath containing a solution which removes all the fluorescent material except that which is entrapped in any flaws or cracks. This part of the process is very much the same as the familiar one of degreasing and, as a secondary advantage attached to the new process, it may be mentioned that the hot bath is actually an eqieient degreasing agent.

After this preparation, each article is examined under ultra-violet light and every small flaw or crack glows with the characteristic colour while the remainder of the specimen remains dark. In this 